\title{
Development of Thin and Lightweight Bulletproof Windows Using Strengthened SLS Glass by Ion Exchange
}

\author{
Gyu-In Shim*, Seong-Hwan Kim*, Deok-Lae Ahn*, Jong-Kyoo Park**, and Se-Young Choi** \\ *Department of Materials Science and Engineering, Yonsei University, Seoul 120-749, Korea \\ **The Fourth Research and Development, Agency for Defense Development, Daejeon 305-152, Korea
}

(Received January 19, 2015; Revised February 23, 2015; Accepted February 24, 2015)

\begin{abstract}
Soda-lime silicate (SLS) glass was strengthened by ion exchange for application of thin and lightweight bulletproof windows. The optimal conditions for ion exchanged SLS glass (thickness of 3 and $10 \mathrm{~mm}$ ) at $480^{\circ} \mathrm{C}$ were 10 and 17 min, respectively. The Vickers hardness values of the strengthened SLS glass samples with thicknesses of 3 and $10 \mathrm{~mm}$ were $5.9 \pm 0.22$ and $6.7 \pm 0.17$ $\mathrm{GPa}$, respectively, which values were about $22 \%$ higher than those of parent SLS glass. By laminating a multilayer defense film and polycarbonate sheet with ion exchanged SLS glass, we were able to make a thin and lightweight bulletproof window (24.25 $\mathrm{mm}, 4.57 \mathrm{~kg}, 50.06 \mathrm{~kg} / \mathrm{m}^{2}, \mathrm{~V}_{50} 901.8 \mathrm{~m} / \mathrm{s}$ ). As a result, the thickness of the bulletproof window was decreased by about $39 \%$ from 40 to $24.25 \mathrm{~mm}$. The light transmittance in the visible range satisfied the standard (over $76 \%$ ) for bulletproof windows.
\end{abstract}

Key words : Soda-lime silicate glass, Ion exchange, Bulletproof window, Ballistic limit velocity, Transmittance

\section{Introduction}

$\mathrm{T}$ ransparent bulletproof windows are variously used for applications such as warships, armored vehicles, and banking facilities. In general, laminated glass for bulletproof windows is penetrated after absorbing the incident energy of a bullet, while the polycarbonate (PC) sheet decreases the rotational energy of the bullet. Therefore, when the glass of a bulletproof window is laminated with PC, the ballistic performance of bulletproof windows can be increased. In recent years, the evaluation of bulletproof materials by considering thickness and stacking sequence of PC sheets is being performed to lead to the manufacture of lightweight and thin bulletproof windows. ${ }^{1,2)}$ However, PC sheet-laminated bulletproof windows show lower transmittance due to the high refractive index of polymer materials in the visible range. The surface hardness of PC sheets is also lower than that of the parent glass. Therefore, it is required to laminate $\mathrm{PC}$ sheets with glass that has higher ballistic performance.

The mechanical properties including flexural strength, Vickers hardness, and fracture toughness of glass are important factors that influence ballistic performance. ${ }^{3)}$ Researchers investigated the influence of cracks on the glass surface during bullet impact. ${ }^{3,4)}$ It was found that it is necessary to improve the ballistic performance of bulletproof windows that have higher crack resistance by strengthening of the glass. There

${ }^{\dagger}$ Corresponding author : Se-Young Choi

E-mail : sychoi@yonsei.ac.kr

Tel : +82-2-2123-2851 Fax : +82-2-312-5375 are many methods for strengthening soda-lime silicate (SLS) glass, including crystallization, ion exchange, and heat treatment. ${ }^{5-7)}$ The crystallization process forms crystal in the glass, strengthening the glass by increasing its crystal volume fraction. However, there are many reports that the transmittance decreases with increasing crystal size inside the glass. The ion exchange method is suitable for strengthening SLS glass due to its resulting in excellent mechanical properties for a very short holding time.

In a pre-experiment, we manufactured a thin and lightweight bulletproof window $(28.25 \mathrm{~mm}$ thickness, $5.70 \mathrm{~kg}$ weight, $63.29 \mathrm{~kg} / \mathrm{m}^{2}$ areal density, $851 \mathrm{~m} / \mathrm{s}$ ballistic limit velocity, 79.3\% light transmittance) with parent SLS glass; the thickness was decreased by about $39 \%$ from 40 to 28.25 $\mathrm{mm}^{5,6)}$ Therefore, research was conducted on the influence on the ballistic limit velocity $\left(\mathrm{V}_{50}\right)$ of strengthened SLS glass instead of parent SLS glass for bulletproof windows. Besides this, the light transmittance was evaluated in the visible range to confirm that this strengthened glass could be used as a bulletproof window according to National Institute of Justice (NIJ-0108.01) standard.

\section{Experimental Procedure}

The chemical composition of SLS glass (Hanglas, Korea) is shown in Table 1 . The edges of the SLS glass specimens of 3 and $10 \mathrm{~mm}$ thickness and dimensions of $310 \mathrm{~mm} \times 310 \mathrm{~mm}$

Table 1. Chemical Composition of the Glass Used (mol\%).

\begin{tabular}{ccccccccc}
\hline Type & $\mathrm{SiO}_{2}$ & $\mathrm{Na}_{2} \mathrm{O}$ & $\mathrm{CaO}$ & $\mathrm{Al}_{2} \mathrm{O}_{3}$ & $\mathrm{~K}_{2} \mathrm{O}$ & $\mathrm{MgO}$ & $\mathrm{TiO}_{2}$ & $\mathrm{Fe}_{2} \mathrm{O}_{3}$ \\
\hline SLS glass & 73.0 & 14.0 & 8.7 & 0.15 & 0.03 & 4.0 & 0.02 & 0.1 \\
\hline
\end{tabular}


were polished using $\mathrm{SiC}$ paper (400-2000 grit) in order to remove the crack in the glass. The SLS glass was covered with $\mathrm{KNO}_{3}$ (Ducsan, Korea) powder in an alumina ceramic 4-wall tray; glass specimens with powder were heated using an electric furnace (Lindberg, Blue M, USA) at $480^{\circ} \mathrm{C}$ for 10 $20 \mathrm{~min}$ to confirm optimized conditions. The penetration depth of $\mathrm{K}^{+}$ions inside the glass was measured by an electron probe microanalyzer (EPMA, JEOL, JAX-8900, Japan).

The SLS glass was laminated with many kinds of polymer films such as polycarbonate (PC, Bayer Inc., Germany), multilayer defense (MD, SKC Inc., Korea), polyvinyl butyral (PVB, Solutia Inc., USA), polyurethane (PU, Noven Inc., USA), and polyester (PET, Berkaert, USA). The bulletproof windows with strengthened SLS glass were laminated in an autoclave (Italmatic, KYL-15, Italy) at $130^{\circ} \mathrm{C}$ for $3 \mathrm{~h}$ after preheating at $90^{\circ} \mathrm{C}$ for $1 \mathrm{~h}$. Table 2 shows the properties (stacking sequence, thickness, weight, and areal density) of the bulletproof windows, which consisted of parent and strengthened SLS glass. Capital letters show which materials were used, such as G (glass), M (MD), and P (PC). Specimen no. 1 (GGPG) was $28.25 \mathrm{~mm}$ thick $^{6)}$ and consisted of one PC sheet $(5 \mathrm{~mm})$ with parent SLS glass. Specimen no. 2 (GMGPGP) was $24.25 \mathrm{~mm}$ thick and consisted of strengthened SLS glass with one MD film $(0.2 \mathrm{~mm})$ and two PC sheets (2 and $4 \mathrm{~mm}$ ).

The Vickers hardness $\left(H_{\mathrm{V}}\right)$ and fracture toughness $\left(K_{\mathrm{IC}}\right)$ of the parent and ion exchanged SLS glass were evaluated using a Vickers microhardness tester (Matsuzawa, Japan). ${ }^{5,6)}$ The applied load of the indent was $4.9 \mathrm{~N}$ with a time of $30 \mathrm{~s} ; 10$ indentations were marked for each specimens. The flexural strength $\left(\sigma_{\mathrm{f}}\right)$ was evaluated using a universal testing machine (Hounsfield, UK). ${ }^{5,6)}$ Rectangular (4 mm wide $\times 36$ $\mathrm{mm}$ long) SLS glass specimens (3 and $10 \mathrm{~mm}$ thickness) were prepared, and a minimum of 10 specimens were evaluated. The light transmittance of the bulletproof windows was measured using a UV/VIS spectrophotometer (Jasco Ltd., V-570, Japan). The scan speed was $1000 \mathrm{~nm} / \mathrm{min}$, with a wavelength range of $300-750 \mathrm{~nm}$. According to the NIJ standard, the transmittance at $24 \mathrm{~mm}$ thickness should be over $76 \%$ in the visible light range.

The ballistic performance test was carried out to assess compliance with the NIJ standard; the incident velocity of an M-16 bullet ( $3.55 \pm 0.1 \mathrm{~g}$ ) was controlled from 850 to 900 $\mathrm{m} / \mathrm{s}$ by regulating the content of the firing charge from 1.26 to $1.27 \mathrm{~g}$. The velocity of the bullet was confirmed using an IR velocity detector (Sugawara Lab. Inc., SPU-3DA, Japan). An $\mathrm{Al}$ witness plate (0.5-mm-thick) was placed $150 \mathrm{~mm}$ behind the bulletproof windows; the experiment was conducted to check whether this plate was protected or not. The energy absorption $(E)$ of the bulletproof windows was calculated as follows: $(1 / 2) \cdot m \cdot V_{50}{ }^{7)}$, where $m$ is the mass of the bullet and $V_{50}$ is the ballistic limit velocity. The specific energy absorption was also calculated to determine whether this material could be used in lightweight and thin bulletproof windows.

\section{Results and Discussion}

Figure 1 shows the mechanical properties of the strengthened and parent SLS glasses with thicknesses of 3 and 10 $\mathrm{mm}$; these values were acquired as a function of the ion exchange time at $480^{\circ} \mathrm{C}$ for $10-20 \mathrm{~min}$. In a pre-experiment, ${ }^{5,6)}$ the duration times of 10 and $17 \mathrm{~min}$ resulted in maximum values for glass with depth of $\mathrm{K}^{+}$ions of 16 and $41 \mu \mathrm{m}$ (thickness of 3 and $10 \mathrm{~mm}$ ), respectively. Especially, the Vickers hardness values of the strengthened SLS glass

Table 2. Bulletproof Windows Consisted of Parent and Strengthened SLS Glass

\begin{tabular}{|c|c|c|c|c|c|c|c|c|c|c|c|c|c|c|c|c|}
\hline \multirow{2}{*}{$\begin{array}{c}\begin{array}{c}\text { Specimen } \\
\text { No. }\end{array} \\
\text { 1. GGPG }\end{array}$} & \multirow{2}{*}{$\begin{array}{c}\begin{array}{c}\text { Glass } \\
\text { type }\end{array} \\
\text { Parent }\end{array}$} & \multicolumn{12}{|c|}{$\begin{array}{c}\text { Stacking sequence from plane-of-incidence of bullet and } \\
\text { thickness of materials }(\mathrm{mm})\end{array}$} & \multirow[t]{2}{*}{$\begin{array}{l}\text { Thickness } \\
(\mathrm{mm})\end{array}$} & \multirow[t]{2}{*}{$\begin{array}{l}\text { Weight } \\
(\mathrm{kg})\end{array}$} & \multirow[t]{2}{*}{$\begin{array}{l}\text { Areal density } \\
\left(\mathrm{kg} / \mathrm{m}^{2}\right)\end{array}$} \\
\hline & & G & PVB & $G$ & $\mathrm{PU}$ & $\mathrm{PC}$ & $\mathrm{PU}$ & $\mathrm{G}$ & PET & & & & & & & \\
\hline & & 10 & 0.7 & 8 & 0.1 & 5 & 0.1 & 4 & 0.35 & & & & & 28.25 & 5.70 & 63.29 \\
\hline \multirow[t]{2}{*}{ 2. GMGPGP } & Strengthened & G & PVB & $\mathrm{MD}$ & PVB & G & PU & $\mathrm{PC}$ & PU & $\mathrm{G}$ & PU & $\mathrm{PC}$ & PET & & & \\
\hline & & 10 & 0.7 & 0.2 & 0.7 & 3 & 0.1 & 2 & 0.1 & 3 & 0.1 & 4 & 0.35 & 24.25 & 4.57 & 50.63 \\
\hline
\end{tabular}

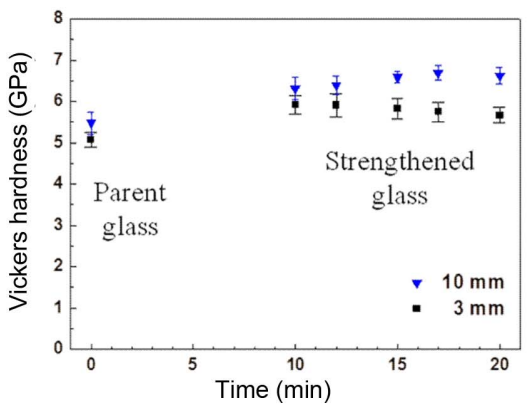

(a)

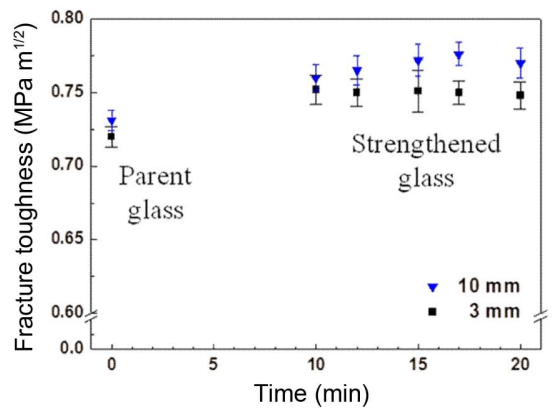

(b)

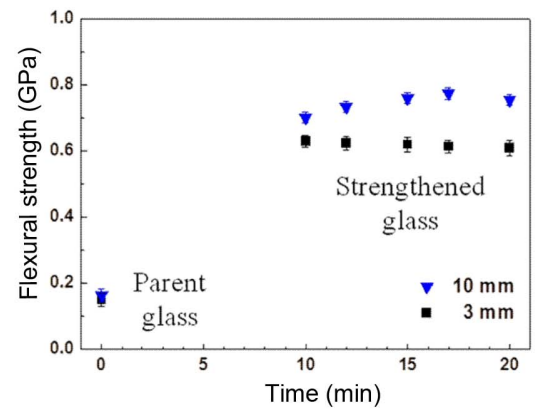

(c)

Fig. 1. Mechanical properties of parent and strengthened SLS glass with various ion exchange times. (a) Vickers hardness, (b) fracture toughness, and (c) flexural strength. 
samples with thicknesses of 3 and $10 \mathrm{~mm}$ were $5.9 \pm 0.22$ and $6.7 \pm 0.17 \mathrm{GPa}$, respectively, which values were about $22 \%$ higher than those values of the parent SLS glass. The values of fracture toughness of the strengthened SLS glass samples with thicknesses of 3 and $10 \mathrm{~mm}$ were $0.752 \pm$ 0.010 and $0.776 \pm 0.008 \mathrm{MPa} \cdot \mathrm{m}^{1 / 2}$, respectively, which values also were $6 \%$ higher than those of the parent glass. The Vickers hardness and fracture toughness values are very important factors for application of lightweight and thin bulletproof material, because the impact energy of a bullet should be decreased. In addition, the flexural strength of the strengthened SLS glass samples with thicknesses of 3 and $10 \mathrm{~mm}$ was $0.630 \pm 0.017$ and $0.774 \pm 0.018 \mathrm{GPa}$, respectively, values that were 3.7 times higher than those of the parent glass. Fig. 2 shows optical micrographs of the indentation when the ion exchanged (Fig. 2(a)) and parent (Fig. 2(b)) glass with thickness of $10 \mathrm{~mm}$ was loaded at 4.9 $\mathrm{N}$. The surface of the parent glass showed radical cracks and shear faults. On the other hand, the strengthened SLS glass showed only an indentation of small size, because the optimal depth of the $\mathrm{K}^{+}$ion was formed on the glass surfaces, and thus the compressive stress layer suppressed the spread of cracks. The impact energy of the bullet was spread, and this caused the formation of cracks. Therefore, the mechanical properties of the glass were found to be related to important factors that affect ballistic performance, such as Vickers hardness and fracture toughness.

Figure 3 shows photographs of the (a) front, (b) back, and (c) Al witness plate of the $24.25 \mathrm{~mm}$-thick bulletproof window (GMGPGP) laminated with ion exchanged glass after

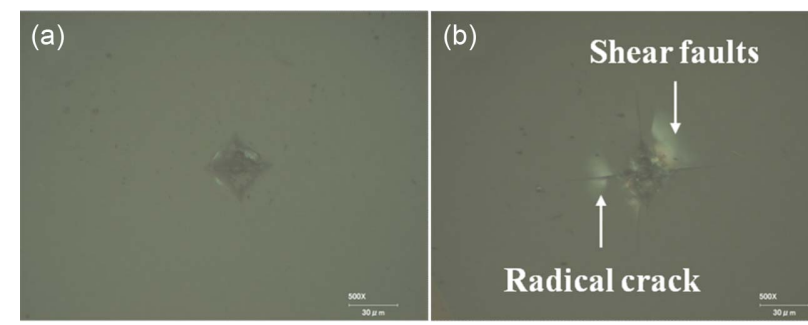

Fig. 2. Optical micrograph of the Vickers indents at a load of $4.9 \mathrm{~N}$ on (a) ion exchanged and (b) parent SLS glass (Scale bar is $30 \mu \mathrm{m}$ ). the ballistic performance test. As can be seen in Fig. 3(a), the impact velocity of the bullet was increased from 870.5 to $925.7 \mathrm{~m} / \mathrm{s}$, and this sample provided protection until the velocity of $887.8 \mathrm{~m} / \mathrm{s}$, as shown in Fig. 3(b). On the other hand, as seen in the results for the final bullet, with velocity of $925.7 \mathrm{~m} / \mathrm{s}$, there was penetration of the witness plate by fragments of the bullet. Therefore, the $V_{50}$ of the GMGPGP bulletproof window was $901.8 \mathrm{~m} / \mathrm{s}$. The bulletproof window of GMGPGP $\left(24.25 \mathrm{~mm}, V_{50} 901.8 \mathrm{~m} / \mathrm{s}\right)$ with strengthened SLS glass, regardless of the $14.2 \%$ decrease in thickness from 28.25 to $24.25 \mathrm{~mm}$, showed improved ballistic performance of about $5.6 \%$ compared to that of the GGPG $\left(28.25 \mathrm{~mm}, V_{50}\right.$ $851.0 \mathrm{~m} / \mathrm{s}$ ) window laminated with parent SLS glass. Furthermore, the GMGPGP bulletproof window laminated with strengthened SLS glass satisfied level III (over $838 \pm 15 \mathrm{~m} / \mathrm{s}$ ) of the NIJ standards. Consequentially, the use of strengthened SLS glass can prevent the propagation of cracks, and therefore the ballistic resistance increases after bullet impact. There was also confirmation that the laminating of a PC sheet between sheets of SLS glass can decrease the ballistic performance of bulletproof window (GGPG): because the PC sheet was laminated between SLS glass sheets, spall can easily form and deliver the impact energy in the behind glass by spalling effect. ${ }^{9)}$ Therefore, the GMGPGP bulletproof window with a PC sheet laminated on the back side increased the impact resistance. In addition, PVB and PC films were also found to be useful materials to increase the ballistic resistance, because these materials can be cured in contact with the strengthened SLS glass to provide superior adhesive strength.

Figure 4(a) - (d) shows the areal density, ballistic limit velocity, energy absorption, and specific energy density, respectively. In order to confirm the influence of the strengthened SLS glass, the energy absorption and specific energy density were calculated. The energy absorption of the GMGPGP (24.25 mm, $\left.V_{50} 901.8 \mathrm{~m} / \mathrm{s}\right)$ bulletproof window increased from $1744 \mathrm{~J}\left(28.25 \mathrm{~mm}, V_{50} 851.0 \mathrm{~m} / \mathrm{s}\right)$ to $1958 \mathrm{~J}$, an increase of $10.9 \%$. The specific energy density was also increased by about $28.6 \%$ from 306 to $428.4 \mathrm{~J} / \mathrm{g}$. In general, brittle materials are affected by the mechanical properties of the target windows such as the Vickers hardness and the fracture toughness. As mentioned earlier, the results can be
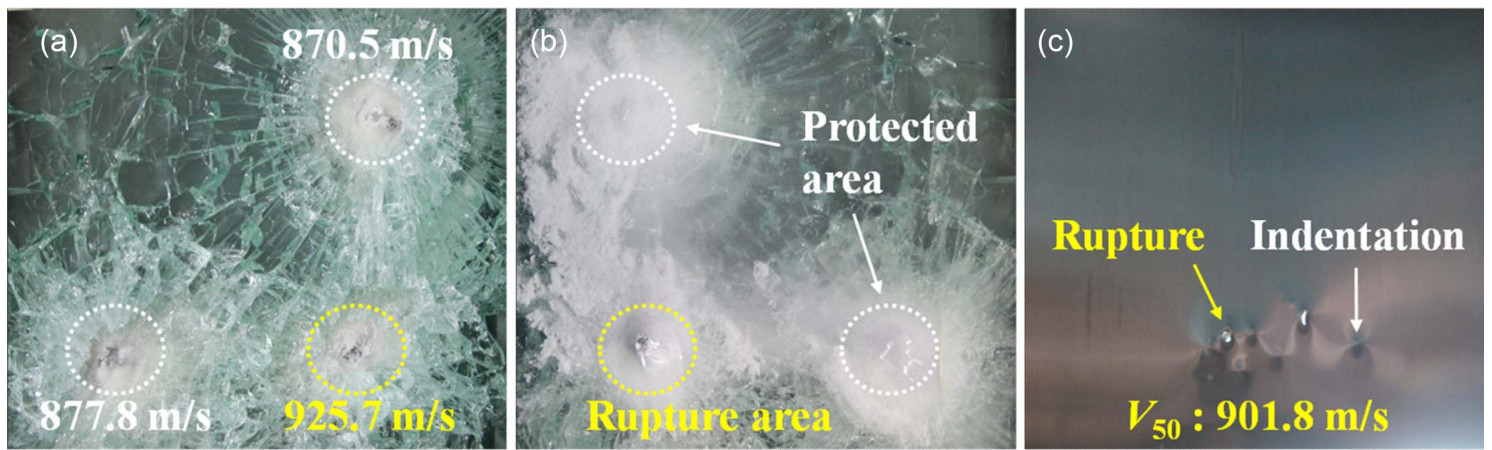

Fig. 3. Photographs of bulletproof window (GMGPGP) after ballistic test: (a) front facing, (b) back facing, and (c) Al witness plate. 


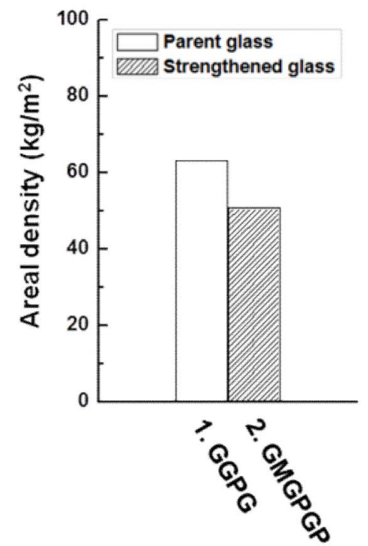

(a)

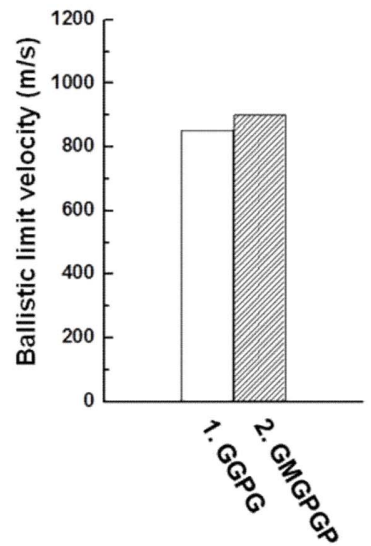

(b)

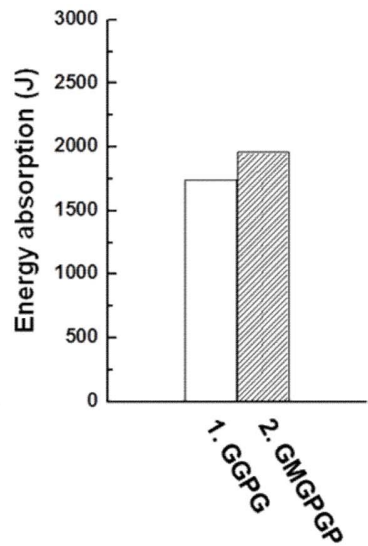

(c)

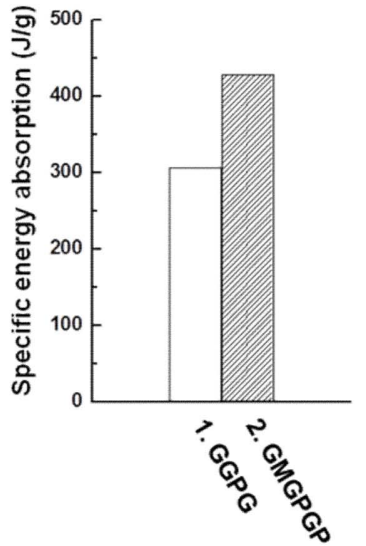

(d)

Fig. 4. Properties of bulletproof materials: (a) areal density, (b) ballistic limit velocity, (c) energy absorption, and (d) specific energy density with different thicknesses.

explained by the strengthening of the glass due to the use of a laminated PC sheet behind the glass. Therefore, we can manufacture a thin and lightweight bulletproof window (GMGPGP) by inserting one MD film and two PC sheet with strengthened glass.

Figure 5 shows the transmittance of the bulletproof windows. The PC-sheet-laminated bulletproof windows appeared to have lower transmittance due to absorption at the wavelength of $672 \mathrm{~nm}$. Nevertheless, the average transmittance of GMGPGP $(24.25 \mathrm{~mm})$ was more than $81.5 \%(84.4 \%$ at wavelength of $550 \mathrm{~nm}$ ), and this satisfies the criteria of 24 mm-thick windows.

\section{Conclusion}

In order to manufacture thin, lightweight, and transparent bulletproof windows, SLS glass was strengthened by ion exchange. The optimal conditions of SLS glass samples of 3 and $10 \mathrm{~mm}$ thicknesses at $480^{\circ} \mathrm{C}$ were 10 and $17 \mathrm{~min}$, respectively, and the $\mathrm{K}^{+}$ion depth values in the SLS glass were 16 and $41 \mu \mathrm{m}$, respectively. Therefore, the Vickers hardness and fracture toughness values of the strengthened glass were increased by about $22 \%$ and $6 \%$, respectively, compared to those values of the parent SLS glass. The bulletproof windows (GMGPGP) were laminated in an autoclave. As a result, the ballistic limit velocity $\left(V_{50}\right)$ increased $5.6 \%$ from 851.0 to $901.8 \mathrm{~m} / \mathrm{s}$, and the thickness decreased $39 \%$ from 40 to $24.25 \mathrm{~mm}$; we were able to make a thin and lightweight bulletproof window (24.25 mm thickness, 4.57 $\mathrm{kg}$ weight, $50.06 \mathrm{~kg} / \mathrm{m}^{2}$ areal density, $901.8 \mathrm{~m} / \mathrm{s} V_{50}, 1958 \mathrm{~J}$ energy absorption, and $428.4 \mathrm{~J} / \mathrm{g}$ specific energy absorption). The light transmittance of the bulletproof window was more than $81.5 \%$, and this value satisfied the NIJ standard (over $76 \%$ ).

\section{Acknowledgments}

This work is supported by the Defense Nano Technology

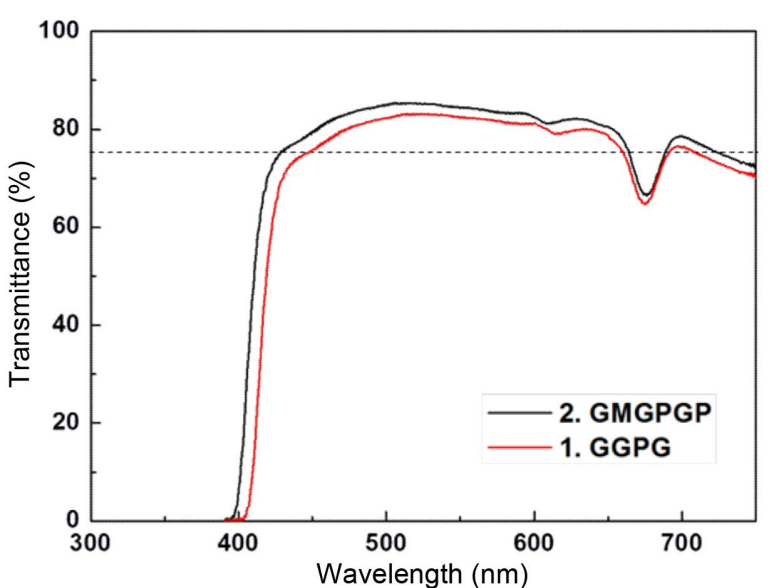

Fig. 5. Transmittance of bulletproof windows with various thicknesses.

Application Center (DNTAC).

\section{REFERENCES}

1. R. Nasirzadeh and A. R. Sabet, "Study of Foam Density Variations in Composite Sandwich Panels Under High Velocity Impact Loading," Int. J. Impact Eng., 63 129-39 (2014).

2. W. Hu, Y. Wang, J. Yu, C. F. Yen, and F. Bobaru, "Impact Damage on a Thin Glass Plate with a Thin Polycarbonate backing," Int. J. Impact Eng., 62 152-65 (2013).

3. M. Grujicic, B. Pandurangan, N. Coutris, B. A. Cheeseman, C. Fountzoulas, P. Patel, and E. Strassburger, "A ballistic Material Model for Starphire ${ }^{\circledR}$ a Soda-lime Transparentarmor Glass," Mater. Sci. Eng. 491 [1-2] 397-411 (2008).

4. B. Sun, Y. Liu, and B. Gu, "A Unit Cell Approach of Finite Element Calculation of Ballistic Impact Damage of 3Dorthogonal Woven Composite," Compos. Pt. B-Eng., 40 [6] 552-60 (2009).

5. G. I. Shim, C. Y. Kim, and S. Y. Choi, "Strengthening of Borosilicate Glass by Controlled Crystallisation for Light- 
weight Bulletproof Materials," Int. J. Nanotechnol., 10 [8] 632-42 (2013).

6. T. Y. Kim, G. I. Shim, and S. Y. Choi, "Effect of SLS Glass for Bulletproof Materials by Ion Exchange Technique," The Korea Inst. of Military Sci. and Technol., 13 114-19 (2010).

7. G. I. Shim, H. W. Eom, S. H. Kim, J. K. Park, and S. Y. Choi, "Fabrication of Lightweight and Thin Bulletproof Windows Using Borosilicate Glass Strengthened by Ion
Exchange," Compos. Pt. B-Eng., 69 44-9 (2015).

8. Z. Feng, C. C. Chou, and K. H. Yang, "Shock Enhancement Effect of Lightweight Composite Structures and Materials," Compos. Pt. B-Eng., 42 [5] 1202-11 (2011).

9. L. Galuppi and G. Royer-Carfagni, "The Effective Thickness of Laminated Glass: Inconsistency of the Formulation in a Proposal of EN-standards," Compos. Pt. B-Eng., 55 109-18 (2013). 